\title{
Effect of Ageing in Structural Properties of ZnO Nanoparticles with pH Variation for Application in Solar Cells
}

\author{
Neetu Singh ${ }^{1}$, Dhruvashi ${ }^{1}$, Davinder $\operatorname{Kaur}^{1}$, R. M. Mehra ${ }^{2}$ and Avinashi Kapoor ${ }^{1{ }_{*}}$ \\ ${ }^{1}$ Department of Electronic Science, University of Delhi South Campus, New Delhi-110021, India \\ ${ }^{2}$ School of Engineering and Technology, Sharda University, Greater Noida-201306 Uttar Pradesh, India
}

\begin{abstract}
ZnO}$ nanoparticles were synthesized via novel Sol-gel route. The effects of $\mathrm{pH}$ variation as well as ageing were studied. The nanoparticles were synthesized with two different $\mathrm{pH}$ levels viz. $\mathrm{pH} 7$ and $\mathrm{pH} 10$. It was found that the size of the nanoparticles increased from 19 to $39.6 \mathrm{~nm}$ with increase in $\mathrm{pH}$ level from 7 to 10 . Further the effect of ageing on the $\mathrm{ZnO}$ nanoparticles was studied. It was found that the crystallite size as well as the crystallinity of the nanoparticles increased with ageing. The crystallite size increased from 19 to $32.8 \mathrm{~nm}$ for $\mathrm{pH} 7$ and from 39.6 to $42 \mathrm{~nm}$ for $\mathrm{pH} 10$ with ageing. The intensity of the XRD peaks increased drastically with ageing primarily due to increase in crystallite size of nanoparticles. The nanoparticles were further characterized using TEM. The particle size obtained by TEM was same as crystallite size obtained by XRD. The synthesized $\mathrm{ZnO}$ nanoparticles can be used as a suitable material for application in quantum dot sensitized solar cells (QDSSCs).
\end{abstract}

Keywords: $\mathrm{ZnO}$ nanoparticles, Sol-gel route, $\mathrm{pH}$, ageing, QDSSC.

\section{INTRODUCTION}

Zinc oxide $(\mathrm{ZnO})$ is a piezoelectric, dielectric and transparent oxide semiconductor, with a direct band gap of $3.37 \mathrm{eV}$ at room temperature and a large excitation binding energy $(60 \mathrm{meV})$, which is 2.4 times the effective thermal energy $(25 \mathrm{meV})$ at room temperature [1]. As in most II-VI materials, the bonding in $\mathrm{ZnO}$ is largely ionic, which explains its strong piezoelectricity. In addition, $\mathrm{ZnO}$ is the hardest of all II-VI semiconductors due to the high melting point $(2248 \mathrm{~K})$ and large cohesive energy $(1.89 \mathrm{eV})$, therefore more resistant to wear. Electron mobility in $\mathrm{ZnO}$ single crystals is about $200 \mathrm{~cm}^{2} / \mathrm{V}$.s [2]. $\mathrm{ZnO}$ crystallizes in three forms: hexagonal wurtzite, cubic zinc blende, and the rarely observed cubic rocksalt. Hexagonal wurtzite is the main stable crystal structure of $\mathrm{ZnO}$ at room temperature [3]. $\mathrm{ZnO}$ has several fundamental advantages over its chief competitor $\mathrm{GaN}$, due to its high energy radiation stability and amenability to wet chemical etching. It is highly transparent and has good electrical conductivity, that is why it is extensively used for various applications such as gas sensor and photovoltaic devices [4-8].

$\mathrm{ZnO}$ is being extensively used in the fabrication of a new class of solar cells namely quantum dot sensitized solar cells (QDSSCs) [9]. It is expected to be an alternating material for $\mathrm{TiO}_{2}$ because of its properties such as being environment friendly, stability, and that it can be synthesized into different shapes and sizes very easily. The schematic diagram of a sandwich type QDSSC using $\mathrm{ZnO}$ nanoparticles as front

*Address correspondence to this author at the Department of Electronic Science, University of Delhi, South Campus, New Delhi-21, India; Tel: +91-11-24116178; Fax: +91-11-24110606;

E-mail: avinashi_kapoor@yahoo.com

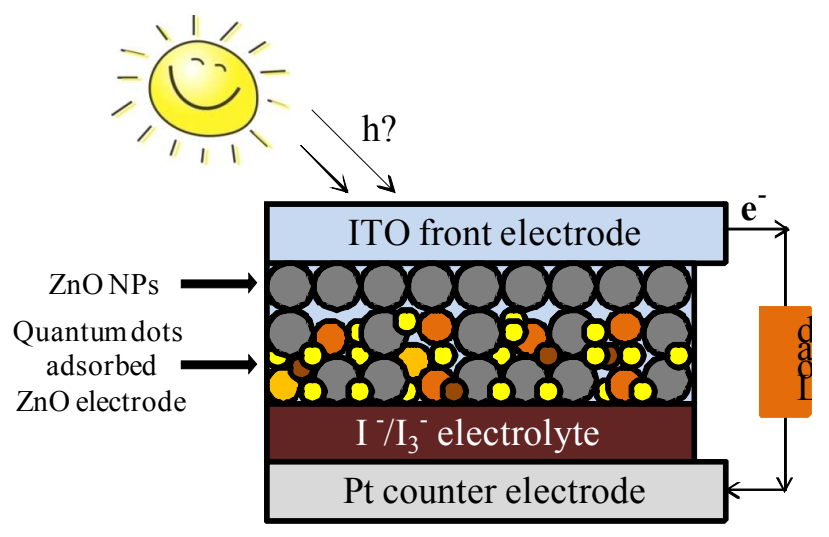

Fig. (1). Schematic diagram of QDSSC using $\mathrm{ZnO}$ as front electrode.

electrode, a thin platinum sheet as counter electrode, quantum dots (QDs) as sensitizer and an electrolyte ( $\mathrm{I}^{-} / \mathrm{I}_{3}{ }^{-}$) is shown in Fig. (1). The front $\mathrm{ZnO}$ electrode passes the photons in the visible range to the underlying QD layer. QDs are excited by uptake of energy contained in photons. The excitation process creates excitons in the QDs. The electrons are then fastly injected into the conduction band of $\mathrm{ZnO}$. The injected electron in the conduction band of $\mathrm{ZnO}$ percolates through the porous $\mathrm{ZnO}$ structure and is fed to the ITO layer. Through ITO, the electron moves to the external circuit. At the Pt counter electrode, triiodide $\left(\mathrm{I}_{3}{ }^{-}\right)$is reduced to iodide (I) by taking the electrons from Pt electrode. $\mathrm{I}^{-}$is transported through the electrolyte towards the ITO photoelectrode, where it reduces the oxidized QD. The QD is then ready for the next excitation/oxidation/reduction cycle. So, here we can see that $\mathrm{ZnO}$ layer plays a major role in functioning of QDSSC. 

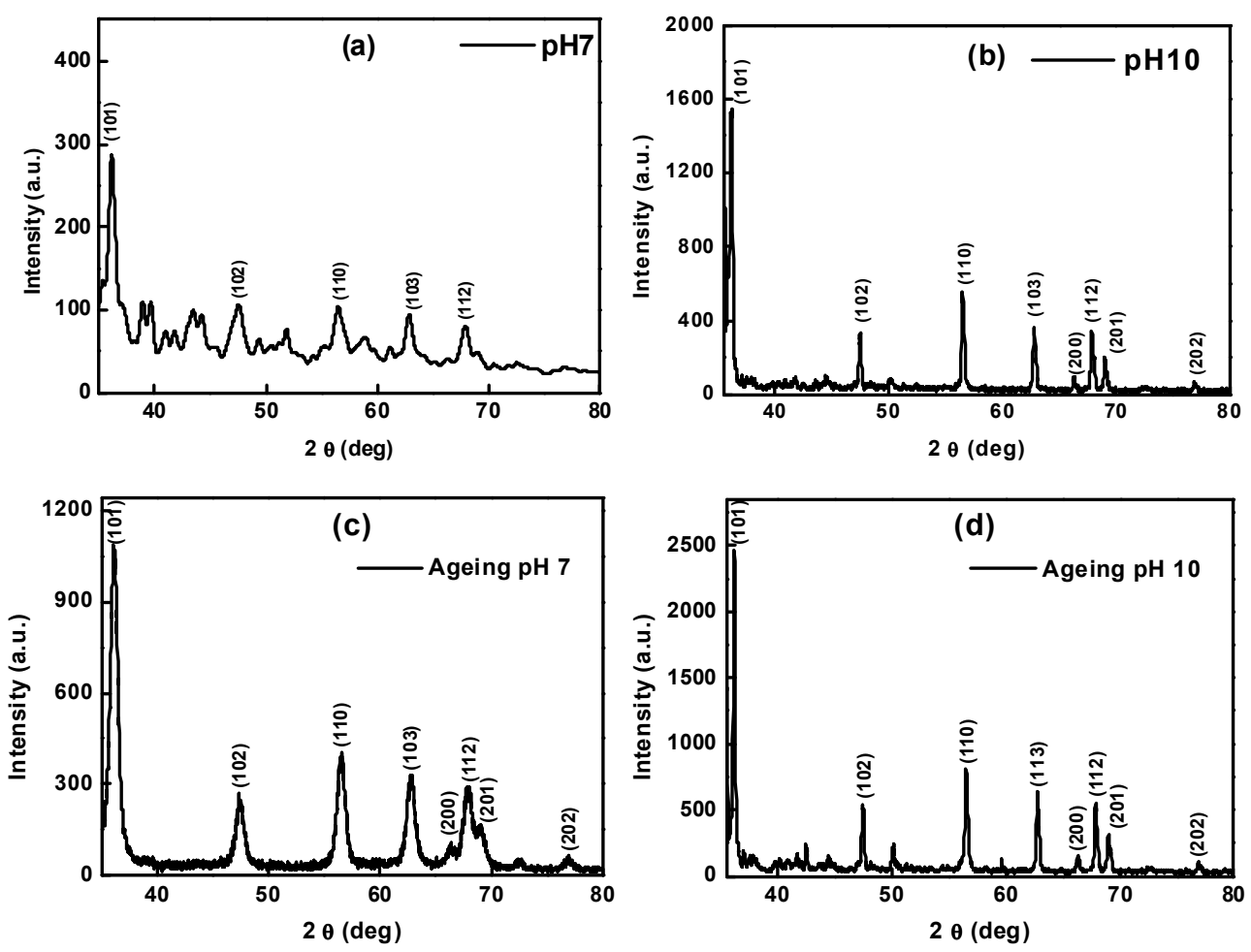

Fig. (2). XRD spectra of $\mathrm{ZnO}$ nanoparticles (a) $\mathrm{pH} 7$ (b) $\mathrm{pH} 10$ (c) ageing pH 7 (d) ageing pH 10.

As compared to other techniques for the synthesis of $\mathrm{ZnO}$ nanoparticles such as solid state reaction method and hydrothermal synthesis, sol-gel technique has a number of advantages such as simplicity, low cost, excellent homogeneity as well as purity of the product (due to availability of highly pure raw materials that can be mixed to atomic levels), relatively low processing temperatures such as room temperature. The other advantages of sol gel process are that the composition and size of the nanoparticles can be controlled. Sol-gel processing has been found to be an economical, convenient and non vacuum method to synthesize homogenous and high quality nanoparticles. This technique is especially useful for growth of $\mathrm{ZnO}$ nanoparticles as well as films, since zinc belongs to the group of elements, that form polymeric hydroxides easily, a fundamental requirement for sol-gel chemistry.

In the present work, we have synthesized $\mathrm{ZnO}$ nanoparticles via novel sol-gel route. Effect of $\mathrm{pH}$ variation and ageing on the structural properties of synthesized $\mathrm{ZnO}$ nanoparticles were studied. As the demand of renewable energy sources is increasing day by day, solar cells such as QDSSCs are extensively researched for better efficiency. As discussed earlier also, the front transparent conducting oxide (TCO) layer of QDSSC is made up of wide bandgap semiconductors such as $\mathrm{ZnO}$. So the synthesized $\mathrm{ZnO}$ nanoparticles will be used in QDSSCs.

\section{MATERIALS AND METHODOLOGY}

Sol-gel is one of the well known techniques for the synthesis of $\mathrm{ZnO}$ nanoparticles as it is easy, has good control over particle size and low cost processing [10]. Nanoparticles were prepared by dissolving $0.2 \mathrm{M}$ Zinc acetate dihydrate $\left[\mathrm{Zn}\left(\mathrm{CH}_{3} \mathrm{COO}\right)_{2} .2 \mathrm{H}_{2} \mathrm{O}\right]$ in methanol at room temperature. Then the solution was mixed ultrasonically for 2 hours at $25^{\circ} \mathrm{C}$ to obtain transparent and clear solution. $\mathrm{NaOH}$ was then added for the desired $\mathrm{pH}$ level ( $\mathrm{pH} 7$ and 10) in the sol [11]. The solution was again stirred ultrasonically for 60 min. The resulting solutions were divided into two parts and kept undisturbed for different time periods. Precipitates collected at the bottom were filtered and washed with excess methanol to remove the starting material. Precipitates were dried for $15 \mathrm{~min}$ at $80^{\circ} \mathrm{C}$ on hot plate.

The XRD measurements were carried out using Bruker AXS - D8 discover diffractometer. The crystallite size calculated from the XRD measurements was confirmed by using TECNAI G ${ }^{2}$ T30, u-TWIN TEM.

\section{RESULTS AND DISCUSSION}

The XRD spectra of $\mathrm{ZnO}$ nanoparticles are shown in Fig. (2). The nanoparticles are highly crystalline as can be seen from the XRD pattern in which broad peaks with high intensity are extended over the $2 \theta$ scale. The diffraction peaks are observed at $2 \theta$ value of $36.25,47.54,56.55,62.87,66.38$, $67.91,69.05$ and $76.95^{\circ}$ corresponding to the lattice planes (101), (102), (110), (103), (200), (112), (201) and (202) respectively, indicative of hexagonal wurtzite structure of $\mathrm{ZnO}$ [12]. All the peaks are matched with standard JCPDS card no. 50664. The broadening of the diffraction peaks gives an idea about the small particle size of the synthesized $\mathrm{ZnO}$. Crystallite size (D), was calculated by using Debye Scherrer's formula,

$\mathrm{D}=\frac{\mathrm{K} \lambda}{\beta \operatorname{Cos} \theta_{\beta}}$

Where, $\mathrm{K}$ is the particle shape factor which depends on the shape of the particles and its value is 0.94 for spherical particles, $\lambda$ is the $\mathrm{CuK}_{\alpha}$ radiations $(1.54 \AA), \beta$ is the full width at half maximum (FWHM) of the selected diffraction peak corresponding to 101 plane and $\theta_{\beta}$ is the Bragg angle obtained from $2 \theta$ value corresponding to the same plane. The 

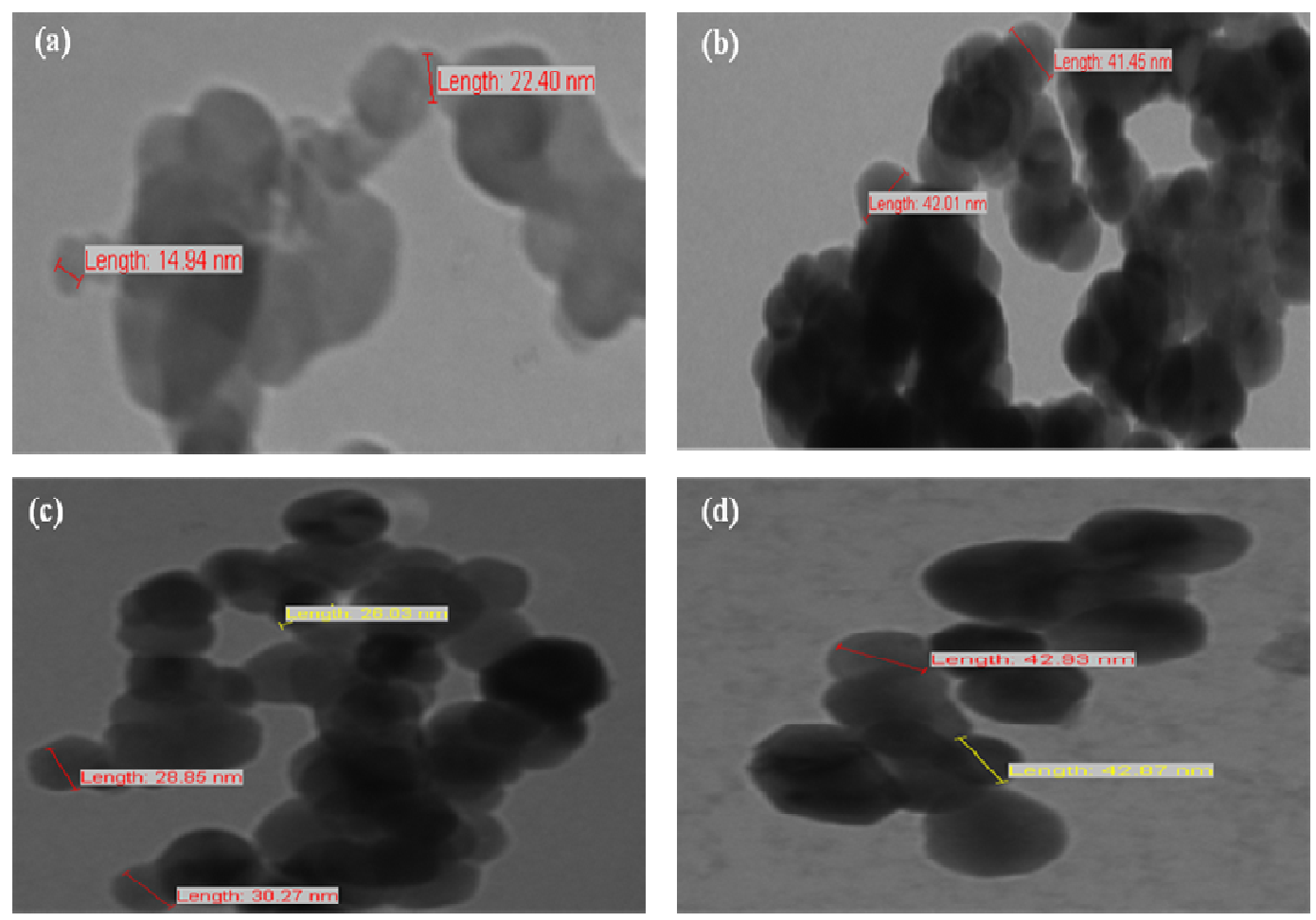

Fig. (3). TEM images of $\mathrm{ZnO}$ nanoparticles (a) $\mathrm{pH} 7$ (b) $\mathrm{pH} 10$ (c) ageing pH 7 (d) ageing pH 10.

crystallite size for $\mathrm{pH} 7, \mathrm{pH} 10$, ageing $\mathrm{pH} 7$ and ageing $\mathrm{pH}$ 10 are obtained to be $19,39.6,32.8$ and $42 \mathrm{~nm}$ respectively.

\section{EFFECT OF PH}

The $\mathrm{ZnO}$ nanoparticle growth from zinc acetate dihydrate precursor using sol-gel process undergoes four stages; solvation, hydrolysis, polymerization and transformation into $\mathrm{ZnO}$ nanoparticles. The zinc acetate dihydrate precursor was first solvated in methanol, and then hydrolyzed which results in a colloidal-gel of zinc hydroxide (Eq. 2). This zinc hydroxide splits into $\mathrm{Zn}^{2+}$ cation and $\mathrm{OH}^{-}$anion (Eq. 3), followed by polymerization of hydroxyl complex to form ' $\mathrm{Zn}$ $\mathrm{O}-\mathrm{Zn}$ ', bridges and finally transformed into $\mathrm{ZnO}$ (Eq. 4)

$\mathrm{ZnO}\left(\mathrm{CH}_{3} \mathrm{COO}\right)_{2} \cdot 2 \mathrm{H}_{2} \mathrm{O}+2 \mathrm{NaOH} \rightarrow \mathrm{Zn}(\mathrm{OH})_{2}+2 \mathrm{CH}_{3} \mathrm{COONa}+2 \mathrm{H}_{2} \mathrm{O}$ (2)

$\mathrm{Zn}(\mathrm{OH})_{2}+2 \mathrm{H}_{2} \mathrm{O} \rightarrow \mathrm{Zn}(\mathrm{OH})_{4}{ }^{+2}+2 \mathrm{H}^{2+}$

$\mathrm{Zn}(\mathrm{OH})_{4}{ }^{+2} \leftarrow \rightarrow \mathrm{ZnO}+\mathrm{H}_{2} \mathrm{O}+2 \mathrm{OH}^{-}$

When $\mathrm{pH}$ is low i.e. concentration of $\mathrm{OH}^{-}$is low, the growth of $\mathrm{ZnO}$ particle does not proceed due to lack of $\mathrm{Zn}(\mathrm{OH})_{2}$ formation in the solution. In this study, the growth of $\mathrm{ZnO}$ nanoparticles in zinc acetate solution was observed from a solution having $\mathrm{pH}$ of 7 . A solution with a $\mathrm{pH} 7$ would have less $\mathrm{OH}^{-}$concentration, so the crystallite size is small $(19 \mathrm{~nm})$ and the diffraction peaks are less intense which can also be seen from XRD pattern. Since $\mathrm{pH}$ controls the rate of $\mathrm{ZnO}$ formation, it affects the size and their way of combination to get stable state. The larger crystallite size $(39.6 \mathrm{~nm})$ was obtained when the $\mathrm{pH}$ of the solution was increased to 10. As the freshly formed nuclei in the solution are unstable, it has a tendency to grow into larger particles.

\section{EFFECT OF AGEING}

XRD patterns of the nanoparticles having $\mathrm{pH} 7$ and 10, after ageing are shown in Fig. (2c) and (2d) respectively. By increasing the ageing period, the FWHM and intensity is observed to be changed. Intensity of the diffraction peak increases due to grain growth of the zinc oxide, due to the Ostwald ripening [13]. Ostwald ripening is an observed phenomenon in solid solutions or liquid sols which describe the change of an inhomogeneous structure over time. Due to large ageing period, small sol particles dissolve and redeposit into larger sol particles and hence the grain size increases [14].

TEM images of the $\mathrm{ZnO}$ nanoparticles with different $\mathrm{pH}$ levels and ageing period are shown in Fig. (3). The results from TEM images are consistent with the observations from XRD. Hexagonal shaped $\mathrm{ZnO}$ nanoparticles have been observed. The particle size is increasing with increase in $\mathrm{pH}$ value as well as with ageing period.

\section{CONCLUSION}

In summary, the effects of $\mathrm{pH}$ variation as well as ageing on the structural properties of Sol-gel synthesized $\mathrm{ZnO}$ nanoparticles were studied. It was found that the size of the nanoparticles increased from 19 to $39.6 \mathrm{~nm}$ with increase in $\mathrm{pH}$ level from 7 to 10 . The crystallite size as well as the crystallinity of the nanoparticles increased with ageing. The crystallite size increased from 19 to $32.8 \mathrm{~nm}$ for $\mathrm{pH} 7$ and from 39.6 to $42 \mathrm{~nm}$ for $\mathrm{pH} 10$ with ageing. The synthesized $\mathrm{ZnO}$ nanoparticles will be used as front wide-bandgap electrode in QDSSCs.

\section{CONFLICT OF INTEREST}

None declared.

\section{ACKNOWLEDGEMENTS}

One the authors, Ms. Neetu Singh gratefully acknowledge University Grant Commission (UGC), India for provid- 
ing finical support in the form of JRF. The authors are also thankful to University Science Instrumentation Centre (USIC) for providing XRD and TEM facility.

\section{REFERENCES}

[1] Nakahara, K.; Takasu, H. Interactions between gallium and nitrogen dopants in $\mathrm{ZnO}$ films grown by radical-source molecular-beam epitaxy. Appl. Phys. Lett., 2001, 25 (79), 4139-4141.

[2] Huston, A. R. Hall effect studies of doped zinc oxide single crystals. Phys. Rev., 1957, 2 (108), 222-230.

[3] Norton, D. P.; Ivill, M.; Li, Y.; Kwon, Y. W.; Erie, J. M.; Kim, H. S.; Ip, K.; Pearton, S. J.; Heo, Y. W.; Kim, S.; Kang, B. S.; Ren, F.; Hebard, A. F.; Kelly, J. Charge carrier and spin doping in $\mathrm{ZnO}$ thin films. Thin Solids Films, 2006, 496, 160-168.

[4] Martin, R.; Fortunato, Nunes, P.; Ferreira, I.; Marques, A.; Bender, M.; Katsarakis, N.; Cimalla, V.; Kiriakidis, G. Zinc oxide as an ozone sensor. J. Appl. Phys., 2004, 3 (96), 1398-1407.

[5] Rao, B. B. Zinc oxide ceramic semi-conductor gas sensor for ethanol vapour. Mater. Chem. Phys., 2000, 64, 62-65.

[6] Fortunato, E.; Goncalves, A.; Marques, A.; Viana, A.; Aguas, H.; Pereira, L.; Ferreira, I.; Vilarinho, P.; Martins, R. New developments in gallium doped zinc oxide deposited on polymeric substrates by RF magnetron sputtering. Surf. Coat. Technol., 2004, (180-181), 20-25.
[7] Singh, N.; Mehra, R. M.; Kapoor, A. Synthesis and characterization of $\mathrm{ZnO}$ nanoparticles. J. Nano-Electron. Phys., 2011, 3 (1), 132139.

[8] Kumar, V.; Singh, R.G.; Purohit L.; Mehra, R.M. Structural, transport and optical properties of boron doped zinc oxide nanocrystalline. J. Mater. Sci. Technol., 2011, 27 (6), 481-488.

[9] Singh, N.; Mehra, R.M.; Kapoor A.; Soga, T. ZnO based quantum dot sensitized solar cell using CdS quantum dots. J. Renewable Sustainable Energy, 2011, 4, 013110.

[10] Ristic, M.; Music, S.; Ivanda, M.; Popovic, S. Sol-gel synthesis and characterization of nanocrystalline $\mathrm{ZnO}$ powders. J. Alloy. Compd., 2005, 397, L1-L4

[11] Daneshvar, N.; Aber, S.; Dorraji, M.S.S.; Khataee, A.R.; Rasoulifard, M.H. Preparation and investigation of photocatalytic properties of $\mathrm{ZnO}$ nanocrystals: effect of operational parameters and kinetic study. Int. J. Chem. Biol. Eng., 2008, 1 (1), 24-29.

[12] Esmaielzadeh kandjani, A.; Shokuhfar, A.; Farzalipour Tabriza, M.; Arefiana, N.A.; Vaezia, M.R. Optical properties of sol-gel prepared nano $\mathrm{ZnO}$. The effects of aging period and synthesis temperature. J. Optoelectron: Adv. Mater., 2009, 3 (11), 289-295.

[13] Xavier, C.S.; Sczancoski, J.C.; Cavalcante, L.S.; Paiva-Santos, C.O.; Varela, J.A.; Longo, E.; Siu Li, M. A new processing method of $\mathrm{CaZn}_{2}(\mathrm{OH})_{6} \cdot 2 \mathrm{H}_{2} \mathrm{O}$ powders: Photoluminescence and growth mechanism. Solid State Sci., 2009, 11, 2173-2179.

[14] Sohnel, O.; Mullin, J.W. Interpretation of crystallization induction periods. J. Colloid. Interface Sci., 1988, 123, 43-50.

Received: January 05, 2012

Revised: January 28, 2012

Accepted: March 15, 2012

(C) Singh et al.; Licensee Bentham Open.

This is an open access article licensed under the terms of the Creative Commons Attribution Non-Commercial License (http://creativecommons.org/licenses/by-nc/3.0/) which permits unrestricted, non-commercial use, distribution and reproduction in any medium, provided the work is properly cited. 